\title{
Increasing Resident Participation in Research: Capitalizing on Local Resources to Maximize Success
}

\author{
Donna M. Windish, MD, MPH, Stephen J. Huot, MD, PhD, Patrick G. O'Connor, MD, MPH, and \\ John P. Moriarty, MD
}

Department of Internal Medicine, Yale University School of Medicine, New Haven, CT, USA.

KEY WORDS: graduate medical education; scholarship; training.

J Gen Intern Med 33(11):1836-8

DOI: $10.1007 / \mathrm{s} 11606-018-4553-0$

(c) Society of General Internal Medicine 2018

\section{INTRODUCTION}

Research participation is required of all residents. ${ }^{1}$ Starting in 2007, the Yale Primary Care Internal Medicine Training Program aimed to improve the quantity and quality of resident research through a structured program capitalizing on local faculty resources.

\section{METHODS}

We implemented stepwise interventions in three phases to enhance resident research.

Phase 1. (Starting 2007-2008) Website development; faculty mentor recruitment

We created web pages containing all documents related to doing research in residency: guidelines, applications, abstract deadlines to select meetings, formatted poster templates, and past residents' abstracts, posters, and oral presentations. ${ }^{2}$ To increase mentor access, we invited 35 Yale General Internal Medicine (GIM) faculty to complete a form delineating their research skills and ideas for resident research projects, then distributed these to house staff.

Phase 2. (Starting 2009-2010) Intern research retreat with GIM faculty; social structure

We developed an annual 2-hour intern research retreat to (1) review research guidelines, (2) provide guidance on finding projects, and (3) increase exposure to GIM faculty mentors over dinner. Fifteen GIM faculty discussed their research in a large group setting.

Phase 3. (Starting 2011-2012) Speed mentoring

Speed mentoring was added to the retreat to promote more faculty/intern interaction. Three to four interns rotated through five groups, each including three faculty mentors, spending 12 min per group to discuss research interests and potential project collaboration.

Published online July 10, 2018

\section{Statistical Analysis}

We compared at the time of graduation baseline residents who did not have any intervention $(n=24)$ [academic years (AY) 2006-2008] to those who experienced: phase $1(n=42$ : AY 2008-2011), phase 2 ( $n=28$ : AY 2011-2013), and phase 3 ( $n=65$ : AY 2013-2017). We used chi-square or Fisher's exact analyses to compare the percent of residents who participated in scholarly projects, total projects conducted, presentations, awards, and publications. We used Cohen's $d$ to determine effect sizes (STATA 14.1, College Station, TX).

Interns in $2017(n=18)$ assessed the retreat with 5-point scaled questions ( $1=$ strongly disagree; $5=$ strongly agree), reported their research motivation before and after the retreat ( 1 = not motivated at all; $4=$ highly motivated $)$, and provided open-ended feedback.

\section{RESULTS}

Compared to baseline $(33.3 \%)$, more residents participated in research during phase $1(69.0 \%, p=0.005)$ and phase 3 $(58.4 \%, p=0.04)$ of our intervention (Table 1$)$. The number of research projects conducted by intervention residents surpassed those at baseline $(33.3 \%)$ : phase $1(83.3 \%$, $p<0.0001)$, phase $2(50 \%, p=0.23)$, and phase $3(87.7 \%$, $p<0.0001$ ) (Fig. 1). Intervention residents had more research presentations compared to baseline $(20.8 \%)$ in all three phases $(p \leq 0.05)$, and won more awards than baseline residents $(4.2 \%)$ in phase $1(26.2 \%), p=0.03)$ and phase $2(32.1 \%$, $p=0.01$ ) (Table 1). There was an increase in publications compared to baseline $(4.2 \%)$ by phase $2(50 \%, p=0.0001)$ and phase $3(21.5 \%, p=0.05)$ residents.

Interns reported higher motivation to do research after the 2017 retreat compared to their pre-retreat ratings (mean 3.61 post vs. 2.72 pre, $p=0.003$ ). Interns felt (1) having dedicated time to learn about research was helpful [mean 4.67 \pm SD $0.49]$, (2) speed mentoring provided them with potential research projects [mean $4.56 \pm 0.62$ ], (3) meeting faculty motivated them to do research [mean $4.50 \pm 0.62$ ], (4) having faculty research project handouts would help them think about research ideas [mean 4.50 \pm 0.79 ], and (5) after the retreat they would contact at least one faculty member they met [mean $4.17 \pm 0.62]$. 


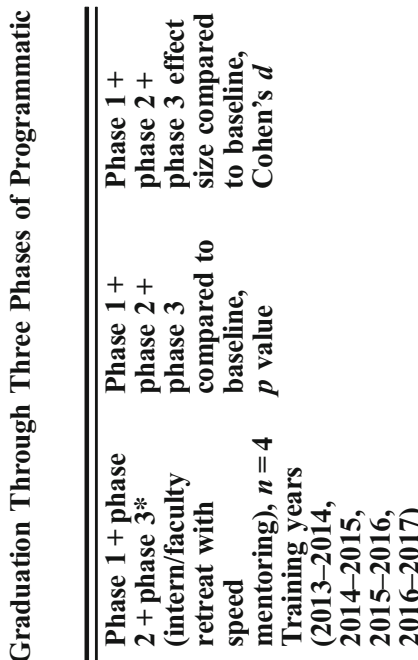

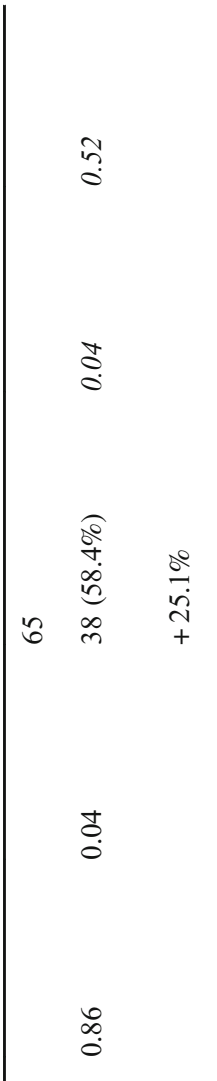

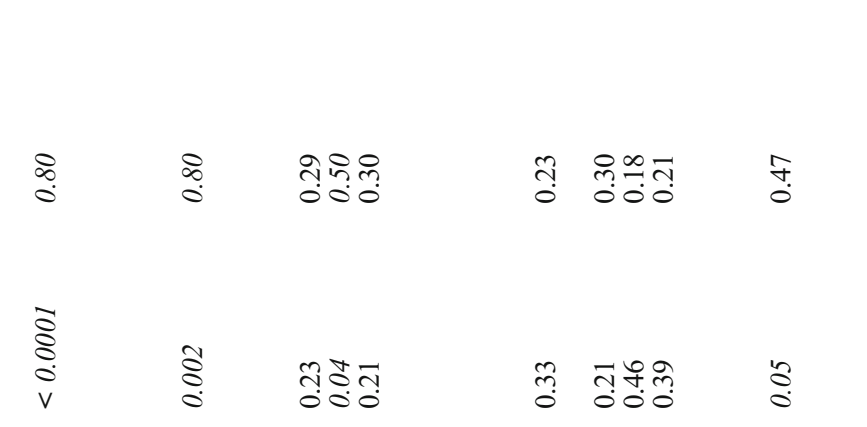

西

苞

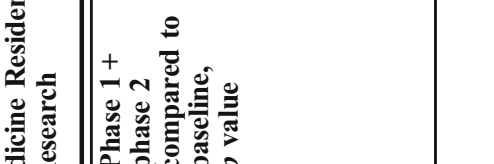

1

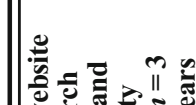

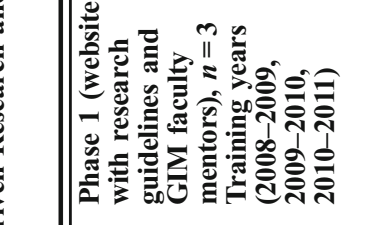

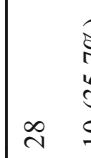

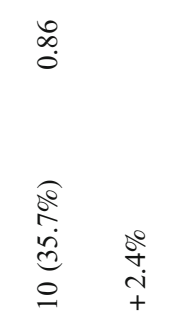

$\stackrel{4}{0}$

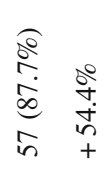

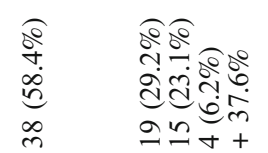

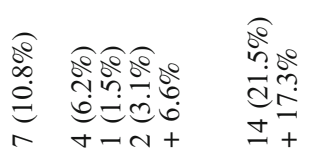

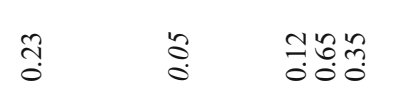

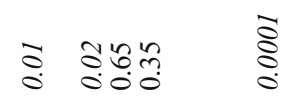

$\stackrel{v}{0}$

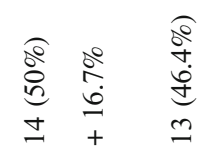

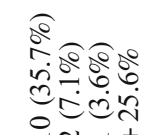

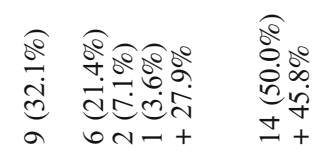

$\stackrel{ }{2} \stackrel{2}{0} \stackrel{=}{=}$

$\stackrel{2}{8}$

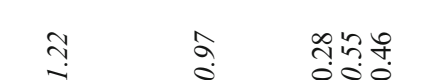

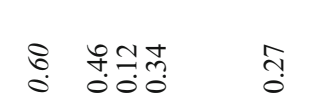

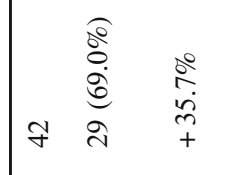

$\grave{\Xi}$
$\grave{8}$
$\dot{0}$
$v$

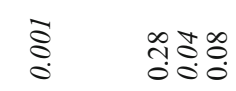

ஜ

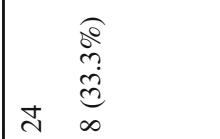

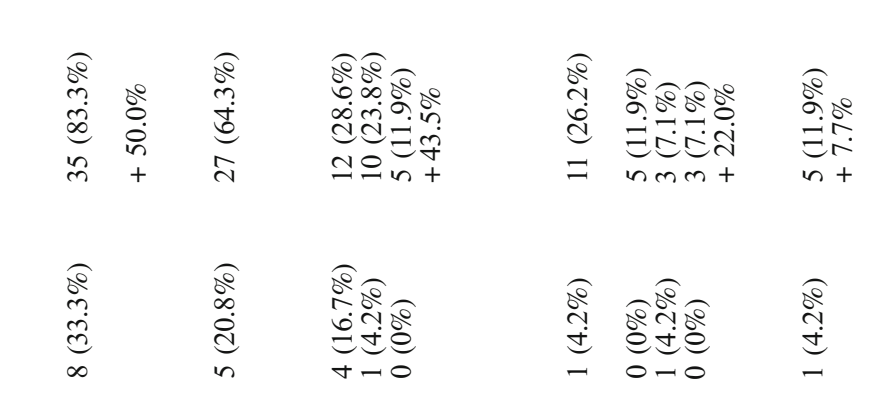

(2)

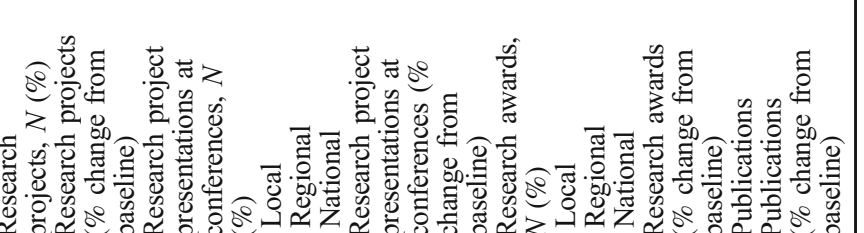




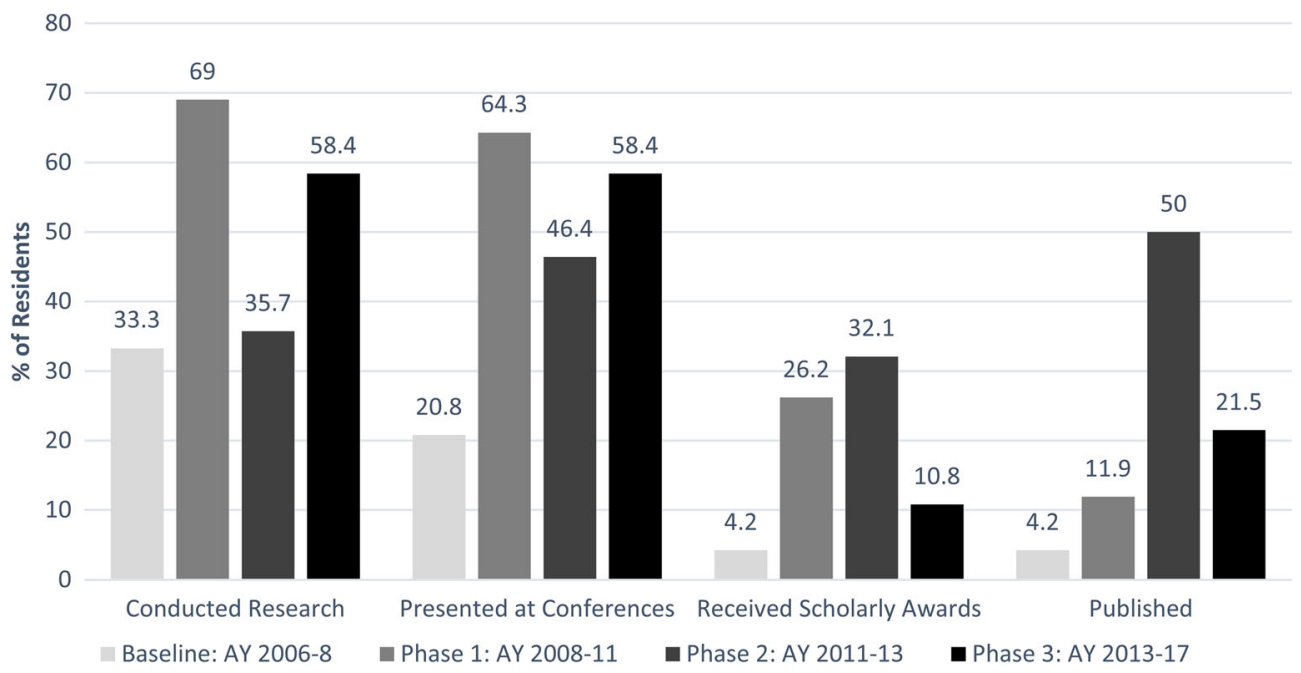

Fig. 1 Changes in resident hypothesis-driven research across 11 graduating years and through three different intervention phases aimed at strengthening and supporting research in residency in the Yale Primary Care Internal Medicine Residency Program.

Twelve interns $(66.7 \%)$ felt speed mentoring was the most useful part of the retreat and $22.2 \%$ felt the handout of faculty projects was most helpful. Two interns $(22.2 \%)$ wanted more information on how to balance research and clinical time.

\section{DISCUSSION}

Our program addressed challenges of residents participating in research in several ways. We provided a structure to participate in research along with access to faculty projects and direct mentor contact through speed mentoring. Speed mentoring is a relatively new concept only sparsely reported in the medical literature. $^{3-5}$ One study of intern/faculty speed "dates" noted increases in resident publications. ${ }^{5}$ No other studies report speed mentoring with faculty during residency.

Limitations of our work include that it was a single training program with a large GIM section actively engaged in research and that we only have formal feedback from our 2017 interns.

Our experience demonstrated that providing a structure for research and capitalizing on local faculty mentors positively influenced resident scholarly productivity.
Corresponding Author: Donna M. Windish, MD, MPH; Department of Internal Medicine, Yale University School of Medicine, New Haven, CT, USA (e-mail: donna.windish@yale.edu).

\section{Compliance with Ethical Standards:}

Conflicts of Interest: The authors declare that they do not have a conflict of interest.

\section{REFERENCES}

1. ACGME Common Program Requirements. https://www.acgme.org/Portals / / PDFs /Specialty-specific\%20Requirement\%20Topics / DIO-Scholarly_Activity_Resident-Fellow.pdf. Accessed 5 June 2018.

2. Yale School of Medicine. Residency Training Program Primary Care: Resident Research and Scholarship. https://medicine.yale.edu/intmed/ residency/pc/curriculum/research/. Accessed on 5 June 2018.

3. Cook DA, Bahn RS, Menaker R. Speed mentoring: an innovative method to facilitate mentoring relationships. Med Teach 2010;32(8):692-4.

4. Guse J, Schweigert E, Kulms G, Heinen I, Martens C, Guse AH. Effects of mentoring speed dating as an innovative matching tool in undergraduate medical education: a mixed methods study. PLoS One 2016;11(2): e0147444.

5. Berquist JB, Carnes M, Roach MA, Vogelman B. 'Speed dating' workshop to pair interns and researchers. Med Educ 2010;44(11):1133-4. 